\title{
Development of an in vitro macrophage screening system on the immunomodulating effects of feed components
}

\author{
S. E. Sivinski ${ }^{1}$, L. K. Mamedova' ${ }^{1}$, R. A. Rusk ${ }^{2}$, C. C. Elrod ${ }^{3}$, T. H. Swartz ${ }^{1}$, J. M. McGill ${ }^{2}$ and B. J. Bradford ${ }^{1,4^{*}}$ (D)
}

\begin{abstract}
Background: While feed components capable of modulating the immune system are highly sought after and marketed, often little evidence is available to support functional immune response claims. Thus, a high-throughput in vitro cell screening system was developed to test these compounds for innate immune signaling effects, using Saccharomyces cerevisiae and its cell wall components in addition to lauric acid and its esters as models in two separate experiments. This screening system utilized RAW 264.7 murine macrophages to assess live $S$. cerevisiae cells and S. cerevisiae-derived cell wall components $\beta$-glucan, mannan, and zymosan (a crude cell wall preparation containing both $\beta$-glucan and mannan). D-mannose was also evaluated as the monomer of mannan. We also examined the effect of a saturated fatty acid (C12:0, lauric acid) and its esters (methyl laurate and glycerol monolaurate) on innate immune cell activation and cellular metabolism. RAW cells were transfected with a vector that drives expression of alkaline phosphatase upon promoter activation of nuclear factor $\mathrm{k}$-light-chain-enhancer of activated B cells (NFkB), a major inflammatory/immune transcription factor. RAW cells were incubated with $0.01,0.1$ or $1 \mathrm{mg} / \mathrm{mL}$ of yeast compounds alone or RAW cells were challenged with LPS and then incubated with yeast compounds. In a separate experiment, RAW cells were incubated with $0,0.5,2.5,12.5,62.5$, and $312.5 \mu \mathrm{mol} / \mathrm{L}$ of lauric acid, methyl laurate, or glycerol monolaurate alone, or RAW cells were challenged with LPS and then incubated with fatty acid treatments.
\end{abstract}

Results: Treatment with zymosan or $\beta$-glucan alone induced NFKB activation in a dose-dependent manner, whereas treatment with D-mannose, mannan, or live $S$. cerevisiae cells did not. Post-treatment with mannan after an LPS challenge decreased NFKB activation, suggesting that this treatment may ameliorate LPS-induced inflammation. Slight increases in NFKB activation were found when fatty acid treatments were applied in the absence of LPS, yet substantial reductions in NFKB activation were seen when treatments were applied following an LPS challenge.

Conclusions: Overall, this cell screening system using RAW macrophages was effective, high-throughput, and sensitive to feed components combined with LPS challenges, indicating modulation of innate immune signaling in vitro.

Keywords: Inflammation, In vitro screening system, NFkB

\footnotetext{
* Correspondence: bjbrad@msu.edu

'Department of Animal Sciences and Industry, Kansas State University, Manhattan 66506, USA

${ }^{4} 2265 \mathrm{~K}$ Anthony Hall, 474 S. Shaw Lane, East Lansing, Ml 48824, USA

Full list of author information is available at the end of the article
}

C The Author(s). 2020 Open Access This article is licensed under a Creative Commons Attribution 4.0 International License, which permits use, sharing, adaptation, distribution and reproduction in any medium or format, as long as you give appropriate credit to the original author(s) and the source, provide a link to the Creative Commons licence, and indicate if changes were made. The images or other third party material in this article are included in the article's Creative Commons licence, unless indicated otherwise in a credit line to the material. If material is not included in the article's Creative Commons licence and your intended use is not permitted by statutory regulation or exceeds the permitted use, you will need to obtain permission directly from the copyright holder. To view a copy of this licence, visit http://creativecommons.org/licenses/by/4.0/ The Creative Commons Public Domain Dedication waiver (http://creativecommons.org/publicdomain/zero/1.0/) applies to the data made available in this article, unless otherwise stated in a credit line to the data. 


\section{Background}

Compounds with immune-modulating capabilities are of increasing interest [1], but in vivo data are expensive and time-consuming to obtain, and thus evidence for feed component-mediated immune effects is often lacking. Therefore, development of an innate immunity in vitro cell screening tool would be useful for determining which compounds to investigate in vivo. To develop this screening system, Saccharomyces cerevisiae and its cell wall components in addition to lauric acid and its esters were used as models in two separate experiments. Saccharomyces cerevisiae is a yeast species commonly used in baking and brewing, and is also popularly supplemented in many mammalian diets. The $S$. cerevisiae cell wall, which is $10 \%$ to $25 \%$ of cell mass, is mostly composed of $\beta$-glucans and mannoproteins consisting of approximately $5 \%$ protein and $25 \%$ to $45 \%$ mannan [2-4]. Zymosan, a crude $S$. cerevisiae cell wall extract, contains approximately $50 \%$ glucans, $20 \%$ mannan, and $15 \%$ proteins [5], and is a commonly used immune stimulant. $\beta$ Glucans of the $S$. cerevisiae cell wall consist of $\beta-1,3-$ linked glucose backbones with $\beta$-1,6-linked glucose branches [2] while cell wall mannan, which can include up to 200 mannose residues, consists of $\alpha$-1,6-linked mannose backbones with $\alpha-1,2-$ and $\alpha-1,3-$ linked branches with up to three mannose residues [6, 7]. These components, along with $S$. cerevisiae cells themselves, impact several aspects of immunity both in vitro and in vivo [8]. Similarly, lauric acid (LA), a medium chain fatty acid (C12:0), and its esters (glycerol monolaurate and methyl laurate) have bactericidal [9-14], antiinflammatory [15], and antioxidant properties [16]. Thus, these feed components serve as models of interest for development of this in vitro screening system.

One central way these feed compounds can influence immunity is through activation of nuclear factor kappalight-chain-enhancer of activated B cells (NFkB). Nuclear factor $\mathrm{\kappa B}$ is an inducible central regulator of inflammatory responses involved in most innate immune receptor signaling pathways, triggering expression of proinflammatory cytokines such as tumor necrosis factor $\alpha$ $(\mathrm{TNF} \alpha)$. The canonical pathway of NFkB activation involves signaling via pattern recognition receptors, including Toll-like receptors (TLR) and C-type lectin-like receptors (e.g., mannose receptor; MR) found on mammalian cells $[17,18]$. After receiving these signals, the inhibitor of kappa B (ІкB) becomes phosphorylated, thus leading to its degradation, and allowing nuclear translocation of NFKB [19]. Reviews on NFKB signaling in inflammation and immunity have been published previously [19-21].

The widely-used RAW 264.7 murine macrophage cell line $[22,23]$ is useful for assessing broad impacts on inflammatory/immune signaling, because the cells are armed with a wide variety of pathogen-associated molecular pattern receptors. We used RAW cells stably transfected with a vector that drives expression of an alkaline phosphatase (AP) reporter gene upon activation of the response elements for NFkB and activator protein 1.

The primary objective of the current study was to determine immune-modulating properties of $S$. cerevisiae components as well as lauric acid and its esters in RAW 264.7 murine macrophages. The secondary objective was to develop a high-throughput innate immune in vitro cell screening tool capable of identifying potential immune-modulating compounds. Our hypothesis was that $S$. cerevisiae cells and their major cell wall component, $\beta$-glucan, would elicit the strongest immune modulation. Similarly, we hypothesized that lauric acid and its esters would attenuate immune activation.

\section{Materials and methods Cell culture protocol}

RAW-Blue ${ }^{\text {tw }}$ cells were derived from RAW 264.7 macrophages (Cat. No. raw-sp; Invivogen, Manassas, VA, USA). These cells were stably transfected with a vector that drives expression of an AP reporter gene upon activation of the response elements for NFkB and activator protein 1. First, thawed cells were transferred to RAW cell initial growth media, which consisted of Minimum Essential Media with $4.5 \mathrm{~g} / \mathrm{L}$ glucose (MEM; Cat No. 11095080; Thermo Fisher Scientific, Waltham, MA, USA), $10 \%$ heat-inactivated fetal bovine serum (FBS), $100 \mu \mathrm{g} / \mathrm{mL}$ Normocin (Cat. No. ant-nr-1; Invivogen), and $2 \mathrm{mmol} / \mathrm{L} L$-glutamine (Cat. No. 25030081; Thermo Fisher Scientific). Cells were centrifuged at $300 \times g$ for $5 \mathrm{~min}$, then the supernatant was discarded and cells were resuspended in $1 \mathrm{~mL}$ initial growth media. Cells were then seeded at $2.5 \times 10^{6}$ cells in initial growth media per $75 \mathrm{~cm}^{2}$ flask. Cells were maintained at $37^{\circ} \mathrm{C}$. Upon reaching approximately $80 \%$ confluency, RAW cells were passaged by gently scraping cells from the flask surface, centrifuging at $300 \times g$ for approximately $7 \mathrm{~min}$, discarding the supernatant, resuspending and centrifuging as before, and finally resuspending in RAW cell maintenance media and seeding them in 75 $\mathrm{cm}^{2}$ flasks. RAW cell maintenance media consisted of MEM with $4.5 \mathrm{~g} / \mathrm{L}$ glucose, $10 \%$ heat-inactivated FBS, 2 $\mathrm{mmol} / \mathrm{L} L$-glutamine, $1 \%$ antibiotic-antimycotic (Cat. No. 15240062; Thermo Fisher Scientific), $100 \mu \mathrm{g} / \mathrm{mL}$ Normocin, and $200 \mu \mathrm{g} / \mathrm{mL}$ Zeocin (Cat. No. ant-zn-1; Invivogen). Cells were passaged again upon achieving approximately $80 \%$ confluency. Using a hemocytometer (Cat. No. 02-671-54; Hausser Scientific, Horsham, PA, USA), RAW cells were counted under a microscope at $10 \times$ magnification. Cells were plated at $1 \times 10^{5}$ cells per well in clear 96-well plates (Cat. No. 353072; Corning, Corning, NY, USA) for AP activity or black-sided, 
clear-bottom 96-well plates (Cat. No. 3603; Corning) for measuring resorufin formation.

In general, reagents used for cell culture and for experiments were the highest purity compounds available from suppliers. However, LPS content was not specifically evaluated in all reagents, and some limited contamination cannot be excluded.

\section{Yeast experiment}

Compounds were added in a dose-titration (log scale) progression. Treatments were $0.01,0.1$, or $1 \mathrm{mg} / \mathrm{mL}$ of $\beta$-glucan (Cat. No. 34-621-025MG; Fisher Scientific, Waltham, MA, USA), D-mannose (Cat. No. M6020-25G; Sigma-Aldrich, St. Louis, MO, USA), mannan (Cat. No. M7504-250MG; Sigma-Aldrich), live yeast cells (type II, Cat. No. YSC2-500G; Sigma-Aldrich), or zymosan (cat. no. Z4250-250MG; Sigma-Aldrich). Treatment concentrations were chosen to represent a broad spectrum of potential doses for the RAW cell system within a range of what has been tested in vitro [24-26]. $\beta$-Glucan, mannan, and zymosan were derived from $S$. cerevisiae. The live $S$. cerevisiae cell treatment was dried by the manufacturer to produce $90 \%$ viable, active cells. Compounds were dissolved in phosphate-buffered saline (PBS), except for $\beta$-glucan, which was suspended in $0.1 \mathrm{mmol} / \mathrm{L}$ sodium bicarbonate. This solution did not alter $\mathrm{NF}_{\mathrm{K} B}$ activation or cellular metabolism compared to PBS diluent (data not shown). To assess the capacity of yeast compounds to aid RAW cells in recovering from an LPS challenge, RAW cells were incubated with $0.1 \mu \mathrm{g} / \mathrm{mL}$ lipopolysaccharide (LPS; Cat. No. L4391; Sigma-Aldrich) for $6 \mathrm{~h}$. Because LPS is known to stimulate NFKB activation, all $180 \mu \mathrm{L}$ of media was then replaced to remove the confounding AP already secreted into cell supernatants. Yeast treatments ( $n=6$ replicates per treatment) were then added directly to the fresh media on top of RAW cells and incubated for $4 \mathrm{~h}$. Experiments assessing the direct effects of yeast treatments alone followed the same protocol previously mentioned but without LPS stimulation during the first $6 \mathrm{~h}$. Unstimulated RAW cells and $0.1 \mu \mathrm{g} / \mathrm{mL}$ LPS-stimulated cells served as controls.

\section{Lauric acid experiment}

Treatments were $0,0.5,2.512 .5,62.5$, and $312.5 \mu \mathrm{mol} / \mathrm{L}$ lauric acid (LA; Cat. No. PHR1580; Sigma-Aldrich), glycerol monolaurate (GML; Natural Biologics, Newfield, NY, USA), or methyl laurate (ML; Natural Biologics). Compounds were dissolved in $0.06 \%$ DMSO (ATCC, Manassas, VA, USA). Cells were challenged with LPS (Cat. No. L9023; Sigma-Aldrich) for $6 \mathrm{~h}$, media was then removed, and lipid treatments were applied for an additional $4 \mathrm{~h}$ ( $n=6$ replicates per treatment). Experiments assessing the direct effects of fatty acid treatments alone followed the same protocol previously mentioned but without LPS stimulation during the first $6 \mathrm{~h}$. Unstimulated RAW cells and $0.1 \mu \mathrm{g} / \mathrm{mL}$ LPS-stimulated cells served as controls. To access potential DMSO effects, we included additional control groups, where cells were only treated with $0.06 \%$ DMSO or DMSO with $0.1 \mu \mathrm{g} /$ mL LPS.

\section{Cellular metabolism}

Cellular metabolism was assessed by resazurin metabolism [27]. In black-walled, clear bottom 96-well plates, $20 \mu \mathrm{L}$ of a $0.15 \mathrm{mg} / \mathrm{mL}$ solution of resazurin sodium salt (Cat. No. R7017-5G; Sigma-Aldrich) was added directly to RAW cells in $200 \mu \mathrm{L}$ of media following treatments. These plates were then incubated for another $4 \mathrm{~h}$. In a preliminary experiment, we assessed the coefficient of variation at 2 and $4 \mathrm{~h}$, and the $4 \mathrm{~h}$ time period was chosen as it minimized inter-assay CV (data not shown). Cellular metabolism was assessed by measuring fluorescent resorufin formation in relative fluorescent units (RFU) after $4 \mathrm{~h}$ of incubation with excitation at $560 \mathrm{~nm}$ and $590 \mathrm{~nm}$ emission using a fluorometric plate reader (Synergy HTX; BioTek Instruments Inc., Winooski, VT, USA) and Gen5 software (BioTek Instruments Inc.).

\section{NFKB activation}

$50 \mu \mathrm{L}$ of cell media from each well was transferred to another 96-well plate containing $150 \mu \mathrm{L}$ of $\mathrm{AP}$ substrate solution per well (QUANTI-Blue; Cat. No. rep-qb1; Invivogen) and incubated for $2 \mathrm{~h}$. In a preliminary experiment, AP activity was assessed every $15 \mathrm{~min}$ starting $30 \mathrm{~min}$ until $6 \mathrm{~h}$ after the addition of AP substrate solution. The $2 \mathrm{~h}$ time point was determined to be suitable as all enzymatic AP curves were increasing but none had reached a plateau (data not shown). To assess NFkB/activator protein 1 activation, AP activity was quantified by determining optical density (OD) at $620 \mathrm{~nm}$ with a colorimetric plate reader (Synergy HTX; BioTek Instruments Inc.) and calculations were performed using Gen5 software (BioTek Instruments Inc.).

\section{Process optimization}

Additional developments in the RAW cell culturing process were required. This included testing multiple sources of FBS because certain FBS sources had background AP activity (data not shown), despite the fact that all FBS sources were heat-inactivated. To test this background variation, $5 \mu \mathrm{L}$ of FBS was added to $45 \mu \mathrm{L}$ of MEM to replicate $10 \%$ of FBS in RAW maintenance media, as would be present in $50 \mu \mathrm{L}$ of RAW cell supernatant when transferred to QUANTI-Blue AP substrate media. This $50 \mu \mathrm{L}$ mixture was then added to $150 \mu \mathrm{L}$ of 
AP substrate media and incubated for $2 \mathrm{~h}$. Absorbance was then measured as previously described. In addition to differences across suppliers, FBS sources from the same company but from different lot numbers had different AP activity. Observed AP activity of media containing GIBCO exosome-free FBS (Cat No. A2720803; ThermoFisher Scientific) did not differ from that of PBS or MEM alone $(P>0.05)$ and was thus used for RAW cell experiments.

\section{Statistical analysis}

Data were analyzed using PROC GLIMMIX (SAS 9.4, SAS Institute Inc.). Fixed effects of compound, LPS, and their interactions were evaluated, with plate as a random effect. If a variable required transformation to meet the assumption of normality, back-transformed means and standard errors are reported according to Jørgensen and Pedersen [28]. Studentized residuals greater than the absolute value of 4 were excluded from analysis. Linear and quadratic contrasts were conducted to evaluate dose-dependent effects. When a factor was found to be significant in the overall model $(P<0.05)$, treatment means were separated using Tukey's HSD test.

\section{Results}

\section{Yeast experiment}

The effect of yeast and yeast components on cellular metabolic activity depended on LPS (Fig. 1; compound $x$ LPS, $P<0.01)$. Where live yeast cells alone reduced cellular metabolism at the $1 \mathrm{mg} / \mathrm{mL}$ concentration $(1 \mathrm{mg} /$ $\mathrm{mL}$ live $S$. cerevisiae vs. CON, $P<0.01$ ), the same concentration of live yeast cells increased metabolism during an LPS challenge $(1 \mathrm{mg} / \mathrm{mL}$ live $S$. cerevisiae LPS vs. CON-LPS, $P<0.01$; quadratic effect yeast $\times$ LPS, $P<0.01$; Table 1). No other effects of yeast or yeast components were found on cellular metabolism; LPS increased cellular metabolism as compared to untreated cells $(P<0.01)$.

For $\mathrm{NF \kappa B}$ activation, yeast and yeast components interacted with LPS (Fig. 2; compound $\times$ LPS, $P<0.01$ ). Quadratic relationships (Table 1) were identified where every yeast and yeast component (all $P<0.01$ ) altered $N F K B$ activation in the absence of an LPS challenge, yet neutral effects or suppression of NFKB activity were observed when treatments were applied following an LPS challenge. In particular, $\beta$-glucan and zymosan at every concentration, as well as $D$-mannose and mannan (1 $\mathrm{mg} / \mathrm{mL})$ and live yeast cells $(0.01$ and $0.1 \mathrm{mg} / \mathrm{mL})$ increased NFKB activation as compared to untreated controls. When RAW cells were stimulated with LPS, $1 \mathrm{mg} /$ $\mathrm{mL}$ mannan reduced $\mathrm{NFKB}$ activation when compared to LPS controls $(P<0.01)$.

\section{Lauric acid experiment}

The effect of lauric acid and its esters on metabolic activity depended on LPS (Fig. 3; compound $\times$ LPS, $P<0.01)$. Quadratic relationships were identified for GML $(P<0.01)$, as treatment had little impact on metabolic activity in the absence of an LPS challenge, yet dose-dependently increased it when GML was applied following an LPS challenge (Table 2). No other fatty acid treatment altered cellular metabolic activity. LPS

\section{Cellular metabolism}

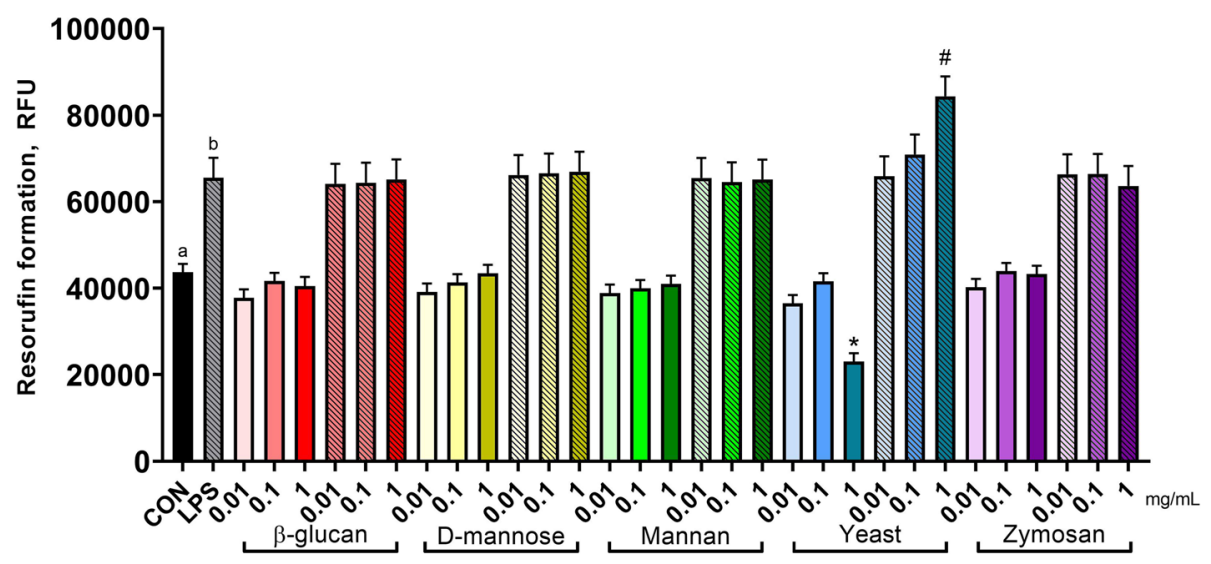

Fig. 1 Metabolic activity of murine macrophages after treatment with components of Saccharomyces cerevisiae. Metabolic activity was assessed by metabolism of resazurin to the fluorescent product resorufin. Untreated RAW cells represent the negative control, and RAW cells stimulated with $0.1 \mathrm{\mu g} / \mathrm{mL}$ LPS served as the positive control. Increasing doses $(0.01,0.1$, or $1 \mathrm{mg} / \mathrm{mL})$ are signified by increasing color intensity within treatment compound. Solid bars indicate control or cells treated with yeast components, whereas patterned bars indicate cells stimulated with LPS or both LPS and yeast components. Values are reported as LSM \pm SE. * indicates means (yeast components alone) differ significantly from CON, \# indicates means (yeast components following LPS) differ significantly from LPS ( $P<0.05$, Tukey's HSD). Different letters indicate means differ $(P<0.05$, Tukey's HSD). Overall, yeast treatment interacted with LPS stimulation (interaction, $P<0.01$ ) on cellular metabolism of resazurin 
Table 1 Linear and quadratic contrasts and interaction contrasts of yeast and yeast components

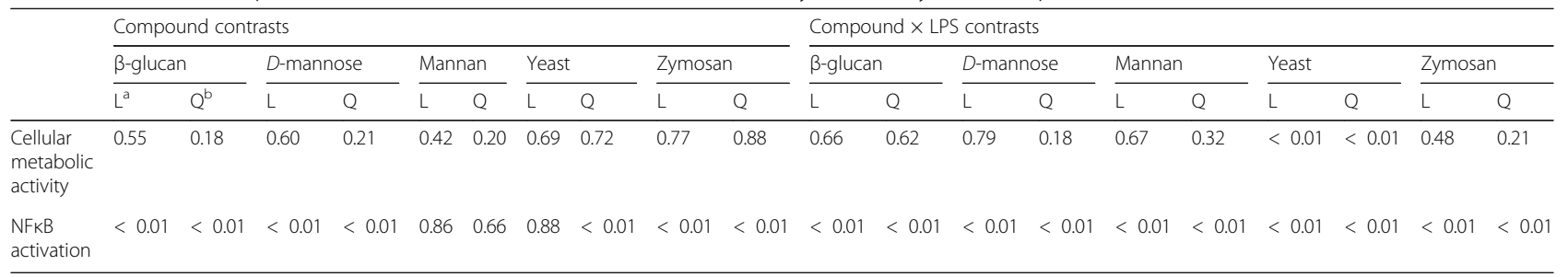

${ }^{2} L$ linear contrast

${ }^{\mathrm{b}} Q$ quadratic contrast

reduced metabolic activity; however, DMSO attenuated this response $(P<0.01)$.

For NFKB activation, lauric acid and its esters interacted with LPS (Fig. 4; compound $\times$ LPS, $P<0.01)$. Quadratic relationships were identified where lauric acid, methyl laurate, and glycerol monolaurate (all $P<0.01$ ) slightly increased NFKB activation in the absence of an LPS challenge, with a far more dramatic dose-dependent reduction in $\mathrm{NF \kappa B}$ activation when treatments were applied following an LPS challenge. Specifically, 62.5 and $312.5 \mu \mathrm{mol} / \mathrm{L}$ concentrations of GML, ML, and LA reduced NFKB activation as compared to the DMSOLPS group (all $P<0.01$ ). Similar to its impact on metabolic activity, DMSO reduced NFKB activation when compared to untreated cells $(P<0.01)$, although this effect was not found in LPS-challenged cells $(P=0.96)$.

\section{Discussion}

Effect of yeast and yeast components on RAW cellular metabolism and activation

Our objective was to develop an in vitro system to test the effects of feed components on immune cell activation. First, we examined the effects of yeast and yeast components alone as well as following an LPS challenge on macrophage cellular metabolism and NFkB activation. Although $\beta$-glucan, $D$-mannose, mannan, and zymosan did not affect cellular metabolism, resazurin metabolism was decreased by treatment with live yeast cells at $1 \mathrm{mg} / \mathrm{mL}$ vs. control. Roy et al. [24] reported lactate dehydrogenase leakage and thus decreased cell viability of murine wound macrophages with exposure to $S$. cerevisiae-derived $\beta$-glucan at $100 \mu \mathrm{g} / \mathrm{mL}$, but not at $20 \mu \mathrm{g} / \mathrm{mL}$. In contrast, we did not observe any decreases in cellular metabolism with $\beta$-glucan across different doses used in our study.

\section{NFKB activation}

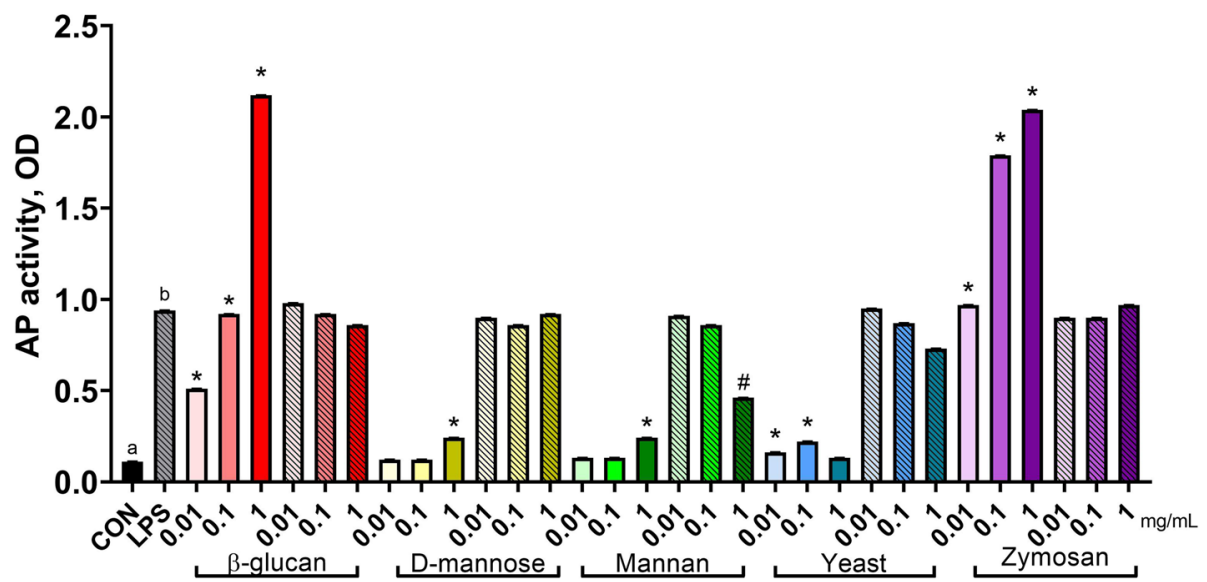

Fig. 2 Nuclear factor $\mathrm{KB}$ activation of murine macrophages treated with components of Saccharomyces cerevisiae. Activity of NFKB was assessed with a reporter plasmid driving expression of alkaline phosphatase (AP). Untreated RAW cells represent the negative control, and RAW cells stimulated with $0.1 \mu \mathrm{g} / \mathrm{mL}$ LPS served as the positive control. Increasing doses $(0.01,0.1$, or $1 \mathrm{mg} / \mathrm{mL})$ are signified by increasing color intensity within treatment compound. Solid bars indicate control or cells treated with yeast components, whereas patterned bars indicate cells stimulated with LPS or both LPS and yeast components. Values were back transformed and reported as LSM $\pm S E$. * indicates means (yeast components alone) differ significantly from CON, \# indicates means (yeast components following LPS) differ significantly from LPS $(P<0.05$, Tukey's HSD). Different letters indicate means differ $(P<0.05$, Tukey's HSD). Overall, yeast treatment interacted with LPS stimulation $(P<0.01)$ on NFKB activation 


\section{Cellular metabolism}

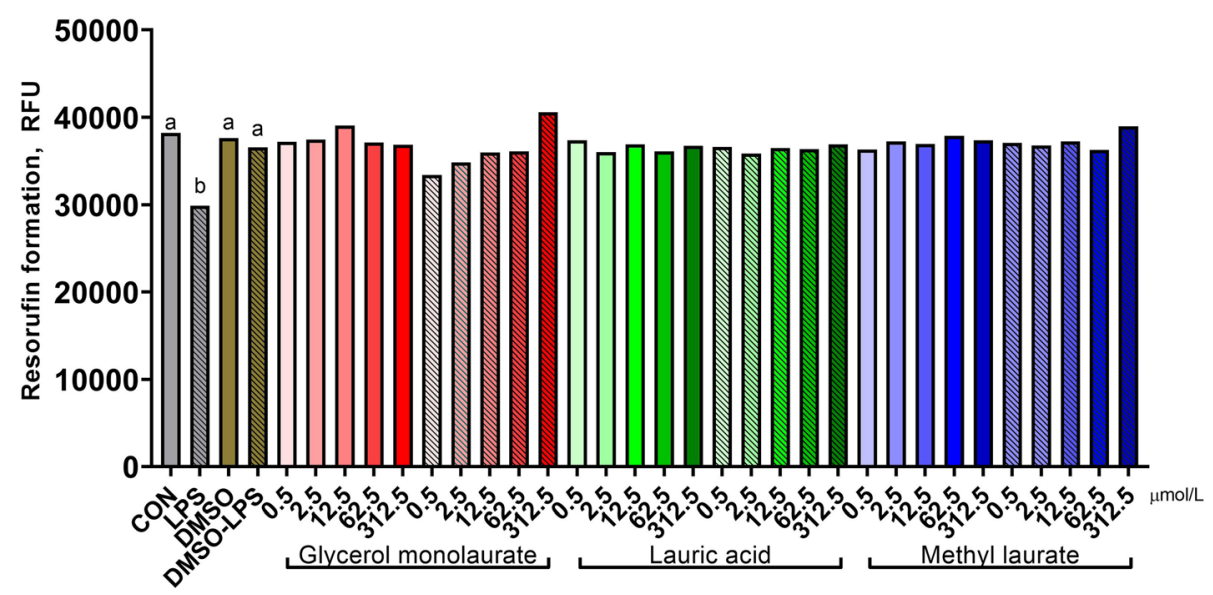

Fig. 3 Metabolic activity of murine macrophages after treatment with lauric acid or its esters. Metabolic activity was assessed by metabolism of resazurin to the fluorescent product resorufin. Untreated RAW cells represent the negative control, and RAW cells stimulated with $0.1 \mu \mathrm{g} / \mathrm{mL} L P S$ served as the positive control. Increasing doses $(0,0.5,2.5,12.5,62.5$, and $312.5 \mu \mathrm{M})$ are signified by increasing color intensity within treatment compound. Solid bars indicate control or cells treated with glycerol monolaurate, lauric acid, or methyl laurate, whereas patterned bars indicate cells stimulated with LPS or both LPS and fatty acids. Values are reported as LSM \pm SE. * indicates means (fatty acids alone) differ significantly from DMSO, \# indicates means (fatty acids following LPS) differ significantly from DMSO-LPS. Different letters indicate means differ $(P<0.05$, Tukey's HSD). Overall, fatty acid treatment interacted with LPS stimulation (interaction, $P<0.01$ ) on cellular metabolism of resazurin

$\mathrm{NFKB}$ activation was affected by yeast compounds in the absence of an LPS challenge. Zymosan is known to induce $N F K B$ activation in macrophages [29-31]; thus, our RAW cell results paralleled previously published results. Walachowski et al. [25] determined that zymosan stimulated the greatest NFKB activation in RAW 264.7 murine macrophages, with similar responses to another crude S. cerevisiae cell wall extract that contained 15\% $\beta$-glucan, 33\% proteins, and 19\% mannans, among other compounds. In contrast, the $S$. cerevisiae cell wall extracts containing $65 \%$ or $75 \% \beta$-glucan, which also consisted of $3.7 \%$ and $<1 \%$ mannan, respectively, weakly induced NFKB activation. These results contrast observations with our purified, particulate $\beta$-glucan source, as well as those reported by McCann et al. [32]. Walachowski et al. [25] also found that TLR2 and TLR4 crosstalk with dectin-1 stimulated greater $\mathrm{NFK}_{\mathrm{K}}$ activity with $\beta$-glucan stimulation. Similarly, Roy et al. [24] reported that S. cerevisiae-derived $\beta$-glucan activated NFKB via TLR2 and dectin-1 in macrophages isolated from murine wounds. Soluble $\beta$-glucan from $S$. cerevisiae can activate NFkB in human [33] and murine [34] macrophage cell lines, though results have not been consistent [25].

Recognition of $\beta$-glucan and zymosan involves dectin-1 and TLR2 [35-37]. Though zymosan contains mannan, a polymer of mannose, the mannose receptor was not predominant in zymosan recognition by macrophages [38]. RAW macrophages also required expression of myeloid differentiation primary response gene 88 (MyD88) to activate NFkB in response to curdlan, a linear particulate $\beta$-1,3-glucan derived from bacteria $[34,39]$. Though $S$. cerevisiae $\beta$-glucans are $\beta-1,3-1,6$-glucan, a $99 \%$ pure linear $\beta$-1,3-glucan was derived from $S$. cerevisiae and similarly stimulated NFkB activation and expression of proinflammatory cytokines [40]. This linear $\beta$-1,3-glucan interacted with TLR2 and complement receptor 3 (CR3). In contrast, blocking CR3 did not affect zymosan recognition by macrophages, suggesting that CR3 recognition depends on structure. However, zymosan required dectin-1, TLR2, and MyD88 to induce TNFo production in murine peritoneal and RAW 264.7 macrophages [35]. Interestingly, RAW 264.7 murine macrophages were shown to

Table 2 Linear and quadratic contrasts and interaction contrasts of lauric acid and its esters

\begin{tabular}{|c|c|c|c|c|c|c|c|c|c|c|c|c|}
\hline & \multicolumn{6}{|c|}{ Compound contrasts } & \multicolumn{6}{|c|}{ Compound $\times$ LPS contrasts } \\
\hline & \multicolumn{2}{|c|}{ Glycerol monolaurate } & \multicolumn{2}{|c|}{ Lauric acid } & \multicolumn{2}{|c|}{ Methyl laurate } & \multicolumn{2}{|c|}{ Glycerol monolaurate } & \multicolumn{2}{|c|}{ Lauric acid } & \multicolumn{2}{|c|}{ Methyl laurate } \\
\hline & $\mathrm{L}^{\mathrm{a}}$ & $Q^{b}$ & $\mathrm{~L}$ & Q & L & Q & $\mathrm{L}$ & Q & L & Q & L & Q \\
\hline Cellular metabolic activity & $<0.01$ & 0.01 & 0.49 & 0.23 & 0.13 & 0.21 & $<0.01$ & $<0.01$ & 0.31 & 0.87 & 0.42 & 0.67 \\
\hline NFkB activation & $<0.01$ & $<0.01$ & $<0.01$ & $<0.01$ & $<0.01$ & $<0.01$ & $<0.01$ & $<0.01$ & $<0.01$ & $<0.01$ & $<0.01$ & $<0.01$ \\
\hline
\end{tabular}

${ }^{a} L$ linear contrast

${ }^{\mathrm{b}} Q$ quadratic contrast 


\section{NFKB activation}

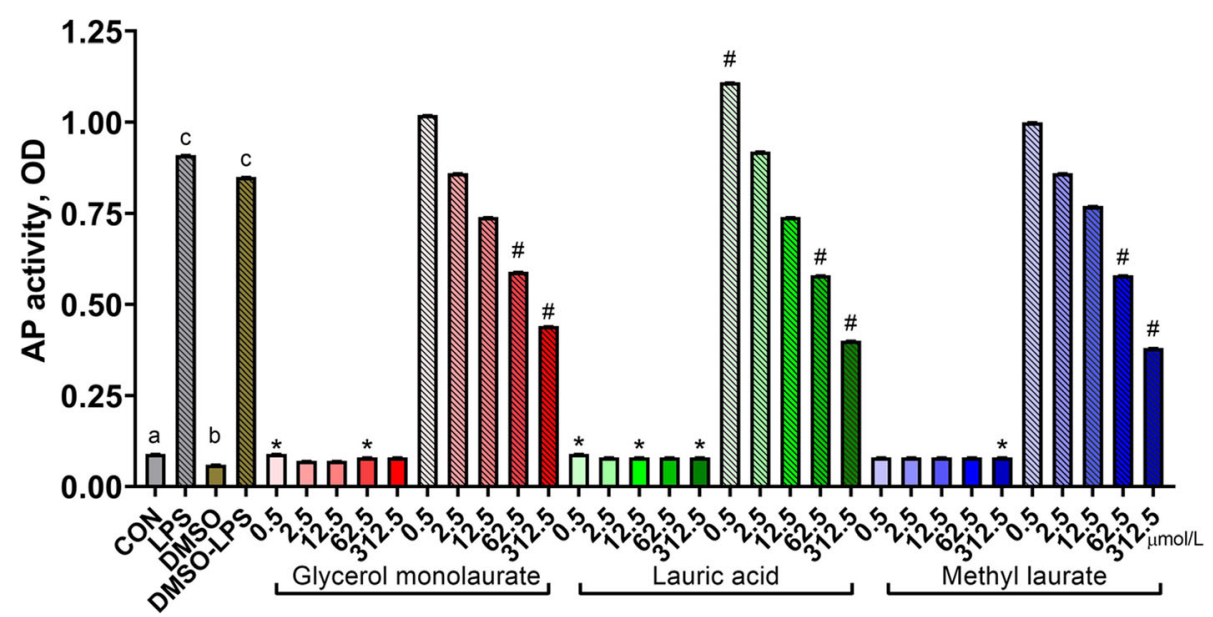

Fig. 4 Nuclear factor KB activation of murine macrophages treated with lauric acid or its esters. Activity of NFkB was assessed with a reporter plasmid driving expression of alkaline phosphatase (AP). Untreated RAW cells represent the negative control, and RAW cells stimulated with $0.1 \mu \mathrm{g} / \mathrm{mL}$ LPS served as the positive control. Increasing doses $(0,0.5,2.5,12.5,62.5$, and $312.5 \mu \mathrm{mol} / \mathrm{L})$ are signified by increasing color intensity within treatment compound. Solid bars indicate control or cells treated with glycerol monolaurate, lauric acid, or methyl laurate, whereas patterned bars indicate cells stimulated with LPS or both LPS and fatty acids. Values are reported as LSM \pm SE. * indicates means (fatty acids alone) differ significantly from DMSO, \# indicates means (fatty acids following LPS) differ significantly from DMSO-LPS. Different letters indicate means differ $(P<0.05$, Tukey's HSD). Overall, fatty acid treatment interacted with LPS stimulation (interaction, $P<0.01$ ) on NFkB activation

express only low levels of dectin-1; greater expression of the receptor led to greater zymosan-induced TNF $\alpha$ production [35]. However, Walachowski et al. [25] reported that dectin-1 expression could be enhanced by incubation with $\beta$-glucans, which further increased TNF $\alpha$ production by this macrophage cell line.

Treatment with $D$-mannose, mannan, and live yeast cells had marginal effects on $\mathrm{NFKB}_{\mathrm{K}}$ activation. Interestingly, live $S$. cerevisiae cells induced greater macrophage binding to the yeast cells and greater TNF $\alpha$ production than live C. albicans [35], which could indicate greater $\mathrm{NF \kappa B}$ activation as well [29]. Mannan from S. cerevisiae induced TNF $\alpha$ production by human monocytes, and required CD14 and TLR4, but not TLR2 [26]; these results suggest that mannan may have activated $N F \kappa B$, the inflammatory transcription factor for TNF $\alpha[19,20,41]$. The mannose receptor (MR) is expressed on macrophages, including RAW 264.7 macrophages [42], and can strongly bind mannose via the manosyl / fucosyl calcium-dependent recognition pattern [43-45]. As mannan has been considered a ligand for this pathway, $S$. cerevisiae mannan could also bind to MR on macrophages to elicit effects $[43,45,46]$. $D$-mannose is also taken up by alveolar macrophages [47] and is recognized by the macrophage MR [46].

\section{Effect of yeast compound treatment after an LPS challenge}

Cellular metabolism was affected by yeast compounds following an LPS challenge. Post-treatment at $1 \mathrm{mg} / \mathrm{mL}$ with live yeast cells resulted in the greatest metabolic activity. Interestingly, while cellular metabolism increased with yeast cell dose, no effect was detected for NFkB activation. Thus, changes in cellular metabolism or viability were most likely not related to NFkB activation. We speculated that the high apparent metabolism of RAW cells exposed to live yeast may have been due to metabolic activity of the yeast itself, and we indeed found that yeast placed in media in the absence of RAW cells showed substantial metabolism of resazurin (data not shown).

Yeast compounds affected NFKB activation following an LPS challenge. Mannan post-treatment at $1 \mathrm{mg} / \mathrm{mL}$ decreased NFKB activity compared to the LPS control, suggesting that mannan could be used as a remedial treatment to LPS-induced inflammation. While literature is lacking on the topic, simultaneous incubation with LPS and mannan from S. cerevisiae did not act synergistically to induce TNF $\alpha$ production in human monocytes, though each compound did elicit this effect independently [26]. In further support of an inflammatory/immuno-regulatory role of mannan from S. cerevisiae, Che et al. [48] observed lesser TNF $\alpha$ production and greater IL-10 production by porcine alveolar macrophages incubated with mannan oligosaccharide. In contrast, post-treatment with $\beta$-glucan, $D$-mannose, live yeast cells, and zymosan did not result in different $\mathrm{NF}_{\kappa} \mathrm{B}$ activation compared to the positive control. This result suggests that these yeast compounds are unable to ameliorate LPS-induced inflammatory signaling, but also do not further potentiate LPS-induced NFkB activation post LPS-challenge. 


\section{Effect of lauric acid esters on cellular metabolism and NFKB activation}

We examined the effect of lauric acid and its esters on macrophage cellular metabolism and $\mathrm{NFK}_{\mathrm{K}} \mathrm{B}$ activation. Resazurin metabolism of RAW macrophages was only marginally affected by fatty acid treatments, with a quadratic effect found with glycerol monolaurate. Past studies have found no effect of lauric acid on macrophage cell viability at lower concentrations (less than $20 \mu \mathrm{mol} / \mathrm{L}$ for $24 \mathrm{~h}$ incubation) [49], although another study with a 48 $\mathrm{h}$ incubation period found cytotoxic effects at greater concentrations $(400 \mu \mathrm{mol} / \mathrm{L})$ [50]. Judging from these studies, lauric acid likely impacts cell viability but only at greater concentrations with longer incubation times than those used in the present study.

Similar to cellular metabolism, lauric acid and its esters had minimal impacts on NFKB activation in the absence of an LPS challenge, although at some concentrations statistically significant increases were found. Past studies discovered that lauric acid increased NFKB activation through TLR2 dimerization with TLR1 or 6, as well as through TLR4 activation [51-54]. Indeed, lauric acid induced dimerization of TLR4 and MD-2 in lipid rafts, which is the initial step in TLR4 signal transduction [55]. However, a recent study demonstrated that another saturated fatty acid, palmitic acid, did not directly activate TLR4 nor did it induce dimerization of TLR4 and MD-2; rather its proinflammatory effects are mediated through shifts in lipidomic profiles due to reprogramming of macrophage metabolism [56]. Similar considerations may be necessary in interpreting signaling responses to lauric acid.

\section{Effect of lauric acid and its esters after an LPS challenge} Lauric acid and its esters did not affect cellular metabolism during an LPS challenge. Intriguingly, LPS reduced cellular metabolism, but DMSO attenuated this response. Because LPS is a pro-inflammatory factor that can have cytotoxic effects, it seems likely that this was abolished by the anti-inflammatory effect of DMSO [57]. When comparing the negative control to the LPS positive control, it is interesting that in the yeast experiment LPS increased cellular metabolism, but in the fatty acid experiment LPS reduced cellular metabolism. Endotoxin sources were different between experiments, suggesting that LPS-induced cellular metabolic responses may be variable due to Escherichia coli strain differences (LPS from E. coli O55: B5 used in the lauric acid experiment vs. LPS from E. coli O111:B4 used in the yeast experiment).

While fatty acid treatment marginally increased $\mathrm{NF}_{\kappa} B$ activation in the absence of an LPS challenge, a sizeable dose-dependent reduction occurred following an LPS challenge. A similar effect was found in microglia postLPS challenge with lauric acid concentrations of 100 to
$200 \mu \mathrm{mol} / \mathrm{L}$ [16], paralleling our study conducted in RAW cells. This biphasic response is likely due to activation of GPR40, a fatty acid receptor [58]. When GPR40 is activated, nitric oxide synthase and reactive oxygen species (ROS) production is partially reduced [16], however, it is still unknown whether this is a direct effect of lauric acid or some other agonist such as a lauric acid metabolite. A reduction in ROS would reduce inflammatory responses and promote resolution, potentially explaining the basis for lauric acid inhibition of NFkB activity. Moreover, lauric acid treatment reduced proinflammatory cytokine concentrations, TNF $\alpha$, IL-6, and IL-1 $\beta$, in cell culture medium from LPS-challenged microglia [16], corroborating our findings that lauric acid reduced NFkB activation in RAW cells. Collectively, these data suggest that lauric acid treatment along with its esters could be used to promote resolution following an inflammatory insult.

\section{Limitations}

This RAW macrophage screening system is based on one simple measurement in vitro, and thus has limitations on what information can be collected. In vitro analysis is limited to certain aspects of inflammatory/immune signaling which cannot replicate the many signaling interactions found in vivo. Most obviously, only one immune cell type was used. Saccharomyces cerevisiae and its components also impact other innate immune cells, including dendritic cells and neutrophils $[31,59,60]$. These cell types also contain $\mathrm{NF}_{\kappa \mathrm{B}}$ and pattern recognition receptors that respond to $S$. cerevisiae components; thus, stimulation with S. cerevisiae components generally results in similar outcomes as macrophages. However, the lack of parenchymal cells as well as adaptive immune cells such as $\mathrm{B}$ and $\mathrm{T}$ lymphocytes may result in missing functional effects of compounds. In this simple cell screening system, potential changes in structure of feed components through the digestive process are lacking, and the bioavailability of some of these components also remains unknown; thus, concentrations of components used in this screening system may not reflect what would be available to immune cells in vivo.

While acknowledging these limitations, our results nonetheless demonstrate the promise of using this screening approach to enable researchers to focus on biomolecules with the greatest potential to influence immune responses. We evaluated yeast components in part because of the strong literature around these compounds both in vitro and in vivo. Consistent with our findings, $\beta$-glucans result in immune modulation in vivo across a wide range of concentrations and species [61-63]. Had this system been used for an initial assessment of components of yeast cells to determine which component to focus on, it likely would have have pointed in the most fruitful direction for further in vivo testing. 


\section{Conclusions}

The in vitro cell screening system using RAW 264.7 murine macrophages was an accurate, quick, sensitive model for determining effects of Saccharomyces cerevisiae and fatty acid components on innate immunity. Assessing cellular metabolic activity also helped to determine if changes in $N_{k} B$ activation due to treatments were related to changes in amount of viable, metabolically-active RAW macrophages. When RAW cells were treated with various yeast compounds alone, zymosan and $\beta$-glucan stimulated the greatest $\mathrm{NF} K \mathrm{~B}$ activation, consistent with many previous reports in various cell types. The use of yeast treatments following an LPS challenge, in particular mannan at $1 \mathrm{mg} / \mathrm{mL}$, was able to attenuate LPS-induced NFKB activation. Lauric acid had minimal impacts on cellular metabolism, regardless of LPS challenge. However, substantial reductions in $\mathrm{NF} \mathrm{KB}$ activation were found when lauric acid was applied following an LPS challenge. In general, the most dramatic results appeared when compounds were tested as a "recovery" agent after endotoxin challenge as compared to their effects alone. Overall, this 2-step in vitro cell screening system was able to detect differences between treatments on macrophages particularly following an endotoxin challenge, suggesting that this may be a fruitful screening strategy.

\section{Acknowledgements}

None.

\section{Authors' contributions}

SES carried out experiments, analyzed data, and drafted the manuscript. LKM and RAR developed methodology and carried out experiments. CCE proposed some treatments and edited the manuscript. THS analyzed results and prepared the final manuscript. JMM and BJB conceptualized the project, oversaw data collection and analysis, and edited the mansucript. All authors read and approved the final manuscript.

\section{Funding}

This work is a contribution from the Kansas Agricultural Experiment Station (Manhattan, KS), supported by USDA National Institute of Food and Agriculture (Washington, DC) Hatch project 1018048 and by support from Cargill Animal Nutrition and Natural Biologics.

\section{Availability of data and materials}

The datasets used and analysed during the current study are available from the corresponding author on reasonable request.

Ethics approval and consent to participate

Not applicable.

\section{Consent for publication}

All authors provide their consent to this publication.

\section{Competing interests}

CCE is an employee and shareholder of Natural Biologics Inc., which develops natural feed additives for animal health applications.

\section{Author details}

'Department of Animal Sciences and Industry, Kansas State University, Manhattan 66506, USA. ²Department of Diagnostic Medicine/Pathobiology, Kansas State University, Manhattan 66506, USA. ${ }^{3}$ Natural Biologics, Newfield, NY 14867, USA. ${ }^{4} 2265$ K Anthony Hall, 474 S. Shaw Lane, East Lansing, MI 48824, USA.
Received: 16 March 2020 Accepted: 9 July 2020

Published online: 01 September 2020

\section{References}

1. Sordillo LM. Nutritional strategies to optimize dairy cattle immunity. J Dairy Sci. 2016;99(6):4967-82.

2. Klis FM, Boorsma A, De Groot PWJ. Cell wall construction in Saccharomyces cerevisiae. Yeast. 2006;23(3):185-202.

3. Orlean P. Architecture and biosynthesis of the Saccharomyces cerevisiae cell wall. Genetics. 2012;192(3):775-818.

4. Lesage G, Bussey H. Cell wall assembly in Saccharomyces cerevisiae. Microbiol Mol Biol Rev. 2006;70(2):317-43.

5. Di Carlo FJ, Fiore JV. On the composition of zymosan. Science. 1958; 127(3301):756-7.

6. Peat S, Turvey JR, Doyle D. The polysaccharides of baker's yeast. Part V. A further study of the mannan. J Chem Soc. 1961;765:3918-23.

7. Ballou L, Hernandez LM, Alvarado E, Ballou CE. Revision of the oligosaccharide structures of yeast carboxypeptidase Y. Proc Natl Acad Sci U S A. 1990;87(9):3368-72.

8. Ganner A, Schatzmayr G. Capability of yeast derivatives to adhere enteropathogenic bacteria and to modulate cells of the innate immune system. Appl Microbiol Biotechnol. 2012;95(2):289-97.

9. Nakatsuji T, Kao MC, Fang J-Y, Zouboulis CC, Zhang L, Gallo RL, et al. Antimicrobial property of Lauric acid against Propionibacterium acnes: its therapeutic potential for inflammatory acne vulgaris. J Investig Dermatol. 2009:129(10):2480-8

10. Kabara JJ, Swieczkowski DM, Conley AJ, Truant JP. Fatty acids and derivatives as antimicrobial agents. Antimicrob Agents Chemother. 1972; 2(1):23-8.

11. Huang W-C, Tsai T-H, Chuang L-T, Li Y-Y, Zouboulis CC, Tsai P-J. Antibacterial and anti-inflammatory properties of capric acid against Propionibacterium acnes: a comparative study with lauric acid. J Dermatol Sci. 2014;73(3):232-40.

12. Schlievert PM, Deringer JR, Kim MH, Projan SJ, Novick RP. Effect of glycerol monolaurate on bacterial growth and toxin production. Antimicrob Agents Chemother. 1992;36(3):626-31.

13. Yoon BK, Jackman JA, Valle-González ER, Cho N-J. Antibacterial free fatty acids and monoglycerides: biological activities, experimental testing, and therapeutic applications. Int J Mol Sci. 2018;19(4):1114.

14. Jackman JA, Boyd RD, Elrod CC. Medium-chain fatty acids and monoglycerides as feed additives for pig production: towards gut health improvement and feed pathogen mitigation. J Anim Sci Biotechnol. 2020. https://doi.org/10.1186/s40104-020-00446-1.

15. Li Q, Estes JD, Schlievert PM, Duan L, Brosnahan AJ, Southern PJ, et al. Glycerol monolaurate prevents mucosal SIV transmission. Nature. 2009; 458(7241):1034-8.

16. Nishimura Y, Moriyama M, Kawabe K, Satoh H, Takano K, Azuma Y-T, et al. Lauric acid alleviates Neuroinflammatory responses by activated microglia: involvement of the GPR40-dependent pathway. Neurochem Res. 2018;43(9):1723-35.

17. Newton K, Dixit VM. Signaling in innate immunity and inflammation. Cold Spring Harb Perspect Biol. 2012;4(3):a006049.

18. Stahl PD, Ezekowitz RA. The mannose receptor is a pattern recognition receptor involved in host defense. Curr Opin Immunol. 1998;10(1):50-5.

19. Liu T, Zhang L, Joo D, Sun S-C. NF-kB signaling in inflammation. Signal Transduct Target Ther. 2017;2:17023.

20. Li Q, Verma IM. NF-KB regulation in the immune system. Nat Rev Immunol. 2002:2:725-34

21. Lawrence T. The nuclear factor NF-KB pathway in inflammation. Cold Spring Harb Perspect Biol. 2009:1(6):a001651.

22. Bognar E, Sarszegi Z, Szabo A, Debreceni B, Kalman N, Tucsek Z, et al. Antioxidant and anti-inflammatory effects in RAW264.7 macrophages of malvidin, a major red wine polyphenol. PLoS One. 2013;8(6):e65355.

23. Merly L, Smith SL. Murine RAW 264.7 cell line as an immune target: are we missing something? Immunopharmacol Immunotoxicol. 2017;39(2):55-8.

24. Roy S, Dickerson R, Khanna S, Collard E, Gnyawali U, Gordillo GM, et al. Particulate $\beta$-glucan induces TNF-a production in wound macrophages via a redox-sensitive NF-k $\beta$-dependent pathway. Wound Repair Regen. 2011; 19(3):411-9.

25. Walachowski S, Tabouret G, Foucras G. Triggering dectin-1-pathway alone is not sufficient to induce cytokine production by murine macrophages. PLoS One. 2016;11(2):e0148464. 
26. Tada H, Nemoto E, Shimauchi H, Watanabe T, Mikami T, Matsumoto T, et al. Saccharomyces cerevisiae- and Candida albicans-derived mannan induced production of tumor necrosis factor alpha by human monocytes in a CD14and toll-like receptor 4-dependent manner. Microbiol Immunol. 2002;46(7): 503-12.

27. Riss TL, Moravec RA, Niles AL, Duellman S, Benink HA, Worzella TJ, et al. Cell viability assays. Assay guidance manual. Bethesda: Eli Lilly \& Company and the National Center for Advancing Translational Sciences; 2004

28. Jørgensen E, Pedersen AR. How to obtain those nasty standard errors from transformed data-and why they should not be used. Biometry research unit-internal report 7. Tjele: Danish Institute of Agricultural Sciences; 1998.

29. Young S-H, Ye J, Frazer DG, Shi X, Castranova V. Molecular mechanism of tumor necrosis factor-a production in $1 \rightarrow 3-\beta$-glucan (zymosan)-activated macrophages. J Biol Chem. 2001;276(23):20781-7.

30. Gantner BN, Simmons RM, Canavera SJ, Akira S, Underhill DM. Collaborative induction of inflammatory responses by dectin-1 and toll-like receptor 2. J Exp Med. 2003;197(9):1107-17.

31. Goodridge HS, Shimada T, Wolf AJ, Hsu Y-MS, Becker CA, Lin X, et al. Differential use of CARD9 by Dectin-1 in macrophages and dendritic cells. J Immunol. 2009;182(2):1146-54.

32. McCann F, Carmona E, Puri V, Pagano RE, Limper AH. Macrophage internalization of fungal $\beta$-glucans is not necessary for initiation of related inflammatory responses. Infect Immun. 2005;73(10):6340-9.

33. Battle J, Ha T, Li C, Beffa VD, Rice P, Kalbfleisch J, et al. Ligand binding to the $(1 \rightarrow 3)-\beta$-D-glucan receptor stimulates NFkB activation, but not apoptosis in U937 cells. Biochem Biophys Res Commun. 1998;249(2):499-504.

34. Adams DS, Pero SC, Petro JB, Nathans R, Mackin WM, Wakshull E. PGGGlucan activates NF-KB-like and NF-IL-6-like transcription factor complexes in a murine monocytic cell line. J Leukoc Biol. 1997;62(6):865-73.

35. Brown GD, Herre J, Williams DL, Willment JA, Marshall ASJ, Gordon S. Dectin-1 mediates the biological effects of $\beta$-glucans. J Exp Med. 2003; 197(9):1119.

36. Taylor PR, Tsoni SV, Willment JA, Dennehy KM, Rosas M, Findon H, et al. Dectin-1 is required for $\beta$-glucan recognition and control of fungal infection. Nat Immunol. 2007;8(1):31-8.

37. Goodridge HS, Wolf AJ, Underhill DM. $\beta$-Glucan recognition by the innate immune system. Immunol Rev. 2009;230(1):38-50.

38. Brown GD, Taylor PR, Reid DM, Willment JA, Williams DL, Martinez-Pomares $L$, et al. Dectin-1 is a major $\beta$-glucan receptor on macrophages. J Exp Med. 2002;196(3):407-12.

39. Kataoka K, Muta T, Yamazaki S, Takeshige K. Activation of macrophages by linear $(1 \rightarrow 3)-\beta-d$-glucans: implications for the recognition of fungi by innate immunity. J Biol Chem. 2002;277(39):36825-31.

40. Zheng $X$, Zou $S, X u H$, Liu Q, Song J, Xu M, et al. The linear structure of $\beta$ glucan from baker's yeast and its activation of macrophage-like RAW264.7 cells. Carbohydr Polym. 2016;148:61-8.

41. Palić D, Andreasen CB, Herolt DM, Menzel BW, Roth JA. Immunomodulatory effects of $\beta$-glucan on neutrophil function in fathead minnows (Pimephales promelas Rafinesque, 1820). Dev Comp Immunol. 2006;30(9):817-30.

42. Jiang H-L, Kim Y-K, Arote R, Jere D, Quan J-S, Yu J-H, et al. Mannosylated chitosan-graft-polyethylenimine as a gene carrier for raw 264.7 cell targeting. Int J Pharm. 2009;375(1):133-9.

43. Fraser IP, Koziel $H$, Ezekowitz RAB. The serum mannose-binding protein and the macrophage mannose receptor are pattern recognition molecules that link innate and adaptive immunity. Semin Immunol. 1998;10(5):363-72.

44. Taylor ME, Bezouska K, Drickamer K. Contribution to ligand binding by multiple carbohydrate-recognition domains in the macrophage mannose receptor. J Biol Chem. 1992;267(3):1719-26.

45. Stahl PD, Schlesinger PH. Receptor-mediated pinocytosis of mannose/Nacetylglucosamine-terminated glycoproteins and lysosomal enzymes by macrophages. Trends Biochem Sci. 1980;5(7):194-6.

46. Gazi U, Martinez-Pomares L. Influence of the mannose receptor in host immune responses. Immunobiol. 2009;214(7):554-61.

47. Shepherd VL, Campbell EJ, Senior RM, Stahl PD. Characterization of the mannose/fucose receptor on human mononuclear phagocytes. J Reticuloendothel Soc. 1982;32(6):423-31.

48. Che TM, Johnson RW, Kelley KW, Dawson KA, Moran CA, Pettigrew JE. Effects of mannan oligosaccharide on cytokine secretions by porcine alveolar macrophages and serum cytokine concentrations in nursery pigs 12. J Anim Sci. 2012:90(2):657-68.
49. Lim W-S, Gan M-S-Y, Ong M-H-L, Chew C-H. Lauric acid abolishes interferongamma (IFN- $)$ )-induction of intercellular adhesion molecule-1 (ICAM-1) and vascular cell adhesion molecule-1 (VCAM-1) expression in human macrophages. Asian Pacific J Reprod. 2015;4(3):217-21.

50. Sheela DL, Narayanankutty A, Nazeem PA, Raghavamenon AC, Muthangaparambil SR. Lauric acid induce cell death in colon cancer cells mediated by the epidermal growth factor receptor downregulation: an in silico and in vitro study. Hum Exp Toxicol. 2019;38(7):753-61.

51. Huang S, Rutkowsky JM, Snodgrass RG, Ono-Moore KD, Schneider DA Newman JW, et al. Saturated fatty acids activate TLR-mediated proinflammatory signaling pathways. J Lipid Res. 2012;53(9):2002-13.

52. Lee JY, Zhao L, Youn HS, Weatherill AR, Tapping R, Feng L, et al. Saturated fatty acid activates but polyunsaturated fatty acid inhibits toll-like receptor 2 dimerized with toll-like receptor 6 or 1. J Biol Chem. 2004;279(17):16971-9.

53. Lee JY, Sohn KH, Rhee SH, Hwang DJ. Saturated fatty acids, but not unsaturated fatty acids, induce the expression of cyclooxygenase-2 mediated through Toll-like receptor 4. J Biol Chem. 2001;276(20):16683-9.

54. Lee JY, Ye J, Gao Z, Youn HS, Lee WH, Zhao L, et al. Reciprocal modulation of toll-like receptor-4 signaling pathways involving MyD88 and phosphatidylinositol 3-kinase/AKT by saturated and polyunsaturated fatty acids. J Biol Chem. 2003;278(39):37041-51.

55. Wong SW, Kwon M-J, Choi AM, Kim H-P, Nakahira K, Hwang DH. Fatty acids modulate toll-like receptor 4 activation through regulation of receptor dimerization and recruitment into lipid rafts in a reactive oxygen speciesdependent manner. J Biol Chem. 2009;284(40):27384-92.

56. Lancaster GI, Langley KG, Berglund NA, Kammoun HL, Reibe S, Estevez E, et al. Evidence that TLR4 is not a receptor for saturated fatty acids but mediates lipid-induced inflammation by reprogramming macrophage metabolism. Cell Metabol. 2018;27(5):1096-110.e5.

57. Kelly KA, Hill MR, Youkhana K, Wanker F, Gimble JM. Dimethyl sulfoxide modulates NF-kappa B and cytokine activation in lipopolysaccharide-treated murine macrophages. Infect Immun. 1994;62(8):3122-8.

58. Houthuijzen JM, Oosterom I, Hudson BD, Hirasawa A, Daenen LGM, McLean CM, et al. Fatty acid 16:4(n-3) stimulates a GPR120-induced signaling cascade in splenic macrophages to promote chemotherapy resistance. FASEB J. 2017;31(5):2195-209.

59. Sonck E, Stuyven E, Goddeeris B, Cox E. The effect of $\beta$-glucans on porcine leukocytes. Vet Immunol Immunopathol. 2010;135(3):199-207.

60. Qi C, Cai Y, Gunn L, Ding C, Li B, Kloecker G, et al. Differential pathways regulating innate and adaptive antitumor immune responses by particulate and soluble yeast-derived beta-glucans. Blood. 2011;117(25):6825-36.

61. Volman JJ, Ramakers JD, Plat J. Dietary modulation of immune function by B-glucans. Physiol Behav. 2008;94(2):276-84.

62. Dalmo RA, Bøgwald J. B-glucans as conductors of immune symphonies. Fish Shellfish Immunol. 2008;25:384-96.

63. Samuelsen ABC, Schrezenmeir J, Knutsen SH. Effects of orally administered yeast-derived beta-glucans: a review. Mol Nutr Food Res. 2014;58:183-93.

Ready to submit your research? Choose BMC and benefit from:

- fast, convenient online submission

- thorough peer review by experienced researchers in your field

- rapid publication on acceptance

- support for research data, including large and complex data types

- gold Open Access which fosters wider collaboration and increased citations

- maximum visibility for your research: over $100 \mathrm{M}$ website views per year

At $\mathrm{BMC}$, research is always in progress.

Learn more biomedcentral.com/submission 